Tema: Aciaria Elétrica

\title{
CARACTERIZAÇÃO DE PÓ DE ACIARIA ELÉTRICA E AVALIAÇÃO DE PROCESSOS DE RECICLAGEM*
}

\author{
Rodrigo Alves Ramos ${ }^{1}$ \\ Mateus Alves Segundo Paulino ${ }^{2}$ \\ Jeferson Leandro Klug ${ }^{3}$
}

\section{Resumo}

Na produção de aços via forno elétrico a arco (FEA) é gerado um resíduo sólido perigoso Classe I, denominado pó de aciaria elétrica (PAE), que é composto principalmente por óxidos metálicos com composição associada aos tipos de sucata utilizados e à composição do aço fabricado. O presente trabalho tem como objetivos centrais: (i) caracterizar amostras deste resíduo oriundas de uma usina siderúrgica localizada no Estado do Ceará, e (ii) avaliar a viabilidade de processos de reciclagem do PAE. A metodologia consiste na caracterização química e estrutural do PAE por meio de análise por fluorescência de raios- $X$ e difração de raios- $X$. Constatou-se a presença dos seguintes elementos: $\mathrm{Zn}, \mathrm{Fe}, \mathrm{Cl}, \mathrm{Pb}, \mathrm{Ca}, \mathrm{K}, \mathrm{Mn}, \mathrm{Si}, \mathrm{Al}$, $\mathrm{S}, \mathrm{Cu}, \mathrm{Ti}$ e $\mathrm{Cr}$, com especial destaque para o $\mathrm{Zn}$ (com teores superiores a $40 \%$ ). As principais fases encontradas no PAE são: franklinita $\left(\mathrm{ZnFe}_{2} \mathrm{O}_{4}\right)$, zincita $(\mathrm{ZnO})$, e magnetita $\left(\mathrm{Fe}_{3} \mathrm{O}_{4}\right)$. Em posse dos resultados, fixa-se no estudo de possibilidades de processos de reciclagem do PAE.

Palavras-chave: PAE; Pó de aciaria elétrica; Reciclagem; Zinco.

\section{ELETRIC ARC FURNACE DUST CHARACTERIZATION AND EVALUATION OF RECYCLING PROCESSES}

\section{Abstract}

On the production of steel by electric arc furnace (EAF) a hazardous waste is generated, named electric arc furnace dust (EAFD), composed by metal oxides whose composition is associated to the manufactured steel composition and to the steel scrap. The present study aims to (i) characterize samples of this residue got from a steelmaking located in the State of Ceará (Brazi) and (ii) evaluate the feasibility of recycling processes of EAFD. The methodology consists in the chemical and structural characterization of the EAFD by analysis by X-rays fluorescence and $\mathrm{X}$-ray diffraction. The following elements were found: $\mathrm{Zn}, \mathrm{Fe}, \mathrm{Cl}, \mathrm{Pb}, \mathrm{Ca}, \mathrm{K}, \mathrm{Mn}, \mathrm{Si}$, $\mathrm{Al}, \mathrm{Br}, \mathrm{S}, \mathrm{Cu}, \mathrm{Ti}$ e $\mathrm{Cr}$. Zinc content is higher than. The main phases in the dust are: franklinite $\left(\mathrm{ZnFe}_{2} \mathrm{O}_{4}\right)$, zincite $(\mathrm{ZnO})$ and magnetite $\left(\mathrm{Fe}_{3} \mathrm{O}_{4}\right)$. Then, the possibilities for recycling processes are studied.

Keywords: EAFD; Eletric arc furnace dust; Recycling; Zinc.

1 Engenheiro Metalúrgico, Departamento de Engenharia Metalúrgica e de Materiais, PPGECM, UFC, Fortaleza, CE, Brasil.

2 Engenheiro Metalúrgico, Aluno de mestrado, Departamento de Engenharia Metalúrgica e de Materiais, PPGECM, UFC, Fortaleza, CE, Brasil.

3 Engenheiro Metalúrgico, Prof. Dr.-Ing, Departamento de Engenharia Metalúrgica e de Materiais, PPGECM , UFC, Fortaleza, CE, Brasil; klug@metalmat.ufc.br.

* Contribuição técnica ao 45 Seminário de Aciaria - Internacional, 25 a 28 de maio de 2014, Porto Alegre, RS, Brasil. 


\section{INTRODUÇÃO}

Em fornos elétricos a arco, forma-se um material complexo oriundo de uma série de fenômenos que envolvem: volatilização dos metais não ferrosos $(\mathrm{Zn}, \mathrm{Pb}, \mathrm{Cd}$, entre outros); ejeção de gotas de aço líquido e de escória ocasionadas pela expansão de bolhas de monóxido de carbono; arraste de partículas sólidas (materiais adicionados ao forno); e, mesmo, atomização [1]. O material em questão é denominado pó de aciaria elétrica (PAE), e é considerado um resíduo da produção do aço, assim como a escória e a carepa. Devido às tais circunstâncias e à sua composição, o PAE é classificado como um resíduo sólido perigoso, Classe I (Não Inerte) de acordo com a norma NBR 10004 [2]. Assim, os órgãos ambientais legais (SEMACE, no caso do estado do Ceará) exigem uma disposição adequada em aterros de resíduos industriais perigosos (ARIPs).

Devido às diferenças de composições dos vários tipos de pós que são gerados, deve-se levar em consideração como variáveis o tipo de forno, o ciclo operacional do aço, o tipo de aço produzido e, em especial, a natureza e a quantidade de sucata e adições que constituem a carga do forno elétrico a arco (FEA) [1].

Nyrenda [3] relatou observações e estudos de diversos autores e apresenta uma breve visão de fases e elementos presentes nos PAEs, baseando-se na formação em atmosfera oxidante e concluindo que mais de $90 \%$ do pó é constituído por óxidos. A Tabela 1 mostra uma abordagem simplificada desses estudos.

Tabela 1. Fases nas quais os elementos se apresentam [1]

\begin{tabular}{|l|l|}
\hline ELEMENTOS & \multicolumn{1}{|c|}{ FASES QUE CONTÊM OS ELEMENTOS } \\
\hline $\mathrm{Zn}$ & $\begin{array}{l}\mathrm{Fe}_{3} \mathrm{O}_{4}, \text { no qual os cátions de } \mathrm{Fe}^{+2}, \text { podem estar substituídos } \\
\text { por } \mathrm{Zn}, \mathrm{Mg}, \mathrm{Cu}, \mathrm{Mn} \text {, etc. }\end{array}$ \\
\hline $\mathrm{Cd}$ & $\begin{array}{l}50-80 \% \text { como zincita }(\mathrm{ZnO}) \text {. A outra parte está principalmente } \\
\text { associado ao Fe e em forma de espinélio } \mathrm{ZnFe}_{2} \mathrm{O}_{4} \text {. Pequenas } \\
\text { quantidades de zinco estão na forma de silicatos, sulfatos ou } \\
\text { aluminatos. }\end{array}$ \\
\hline $\mathrm{Pb}$ & $\begin{array}{l}\text { Distribuição não muito bem estabelecida, mas possivelmente } \\
\text { como o zinco, considerando algumas semelhanças entre os } \\
\text { dois elementos. }\end{array}$ \\
\hline $\mathrm{Cr}, \mathrm{Ni}$ & $\begin{array}{l}\text { Principalmente como óxido. O } \mathrm{PbSO}_{4} \text { e } \mathrm{PbCl}_{2} \text { estão também } \\
\text { presentes. }\end{array}$ \\
\hline $\mathrm{Ca}$ & $\begin{array}{l}\text { Substituindo o Fe na } \mathrm{Fe}_{3} \mathrm{O}_{4}, \text { estrutura do tipo espinélio, algum } \\
\text { Cr pode estar na forma } \mathrm{Cr}_{2} \mathrm{O}_{3} .\end{array}$ \\
\hline $\mathrm{Cl}, \mathrm{Na}, \mathrm{F}, \mathrm{K}$ & $\begin{array}{l}\text { Como CaO e CaCO } \\
\text { fluoreto, ferrita ou silicato. }\end{array}$ \\
\hline
\end{tabular}

A fabricação de aço é sempre acompanhada da emissão de grande quantidade de poeira, a qual é carregada dos fornos por meio de sistemas exaustores e armazenada em silos (ou bags) adequados. Uma série de pesquisadores no mundo têm-se proposto a relatar os índices de geração de PAE, e estudos mostram que os mesmos encontram-se na faixa de $15-20 \mathrm{~kg} /$ tonelada de aço produzido [1], sendo também relatados valores inferiores $(1,5-2 \mathrm{~kg})$. Tais valores demonstram que as grandes quantidades têm sido geradas e sua disposição em ARIPs, que teve seu preço aumentado consideravelmente nos últimos anos devido às maiores exigências de monitoramento por parte dos órgãos responsáveis, não é configura uma situação

\footnotetext{
* Contribuição técnica ao 450 Seminário de Aciaria - Internacional, 25 a 28 de maio de 2014, Porto Alegre, RS, Brasil.
} 
ideal. Assim, torna-se importante o estudo e a viabilização de alternativas para a reciclagem do PAE.

No mundo, desde a última década tem crescido a razão de reciclagem de PAE, como se pode observar nos dados da Figura 1.

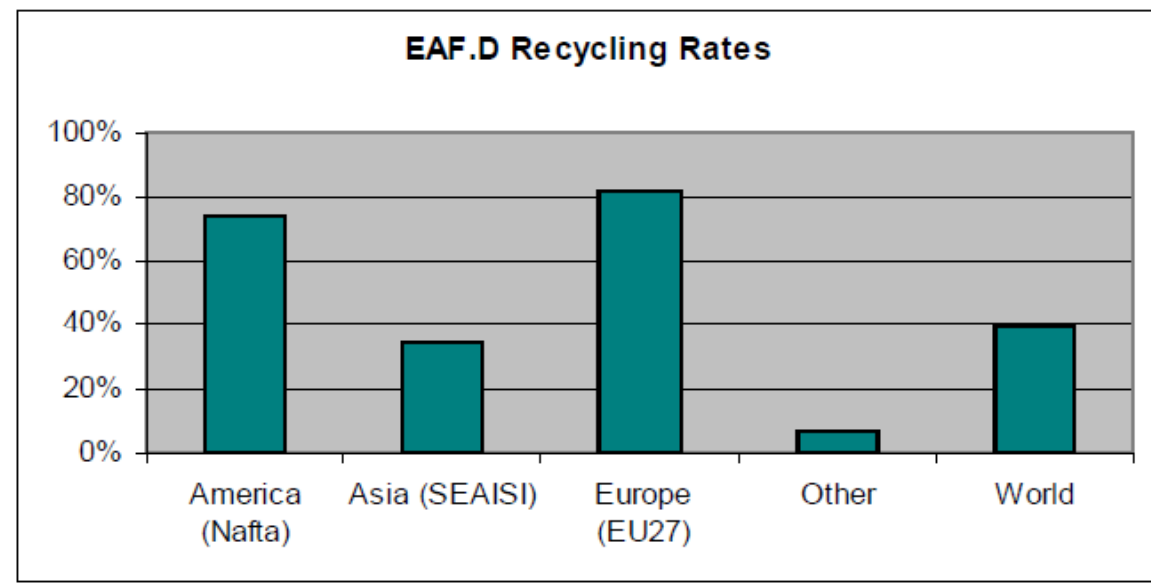

Figura 1. Taxas de reciclagem de PAE [4].

Há uma tendência mundial, especialmente em países desenvolvidos, em atrelar a reciclagem de PAE à recuperação de zinco (nas formas de $\mathrm{Zn}$ ou $\mathrm{ZnO}$ ), uma vez que, como ficará claro durante as próximas seções, este resíduo geralmente possui quantidades significativas - \pm 11 a $45 \%$ - do mesmo [3]. A razão da presença considerável de $\mathrm{Zn}$ é justificada pela comum presença de materiais galvanizados na matéria-prima das usinas mini-mills (na sucata de aço) A reciclagem do PAE, na verdade, representa o fechamento de um ciclo de reciclagem de aço (via siderurgia) e reciclagem de $\mathrm{Zn}[4]$.

Através da Figura 1 observa-se que há perda significativa de potencial fonte de zinco, em especial no Brasil, onde rotas de reciclagens são inferiores a $10 \%$. Em nosso país, as principais propostas de aproveitamento objetivam o retorno ao processo produtivo ou sua adição como matéria-prima em outros processos [5]. Isso representa espaço para estudo e inovação tecnológica no mercado brasileiro junto aos grandes grupos siderúrgicos.

É realidade que a maioria dos processos emergentes para o tratamento de poeiras encontra-se em fase de estudo, tanto a modelos laboratoriais quanto a plantas pilotos, porém é consenso que as rotas de tratamento enquadram-se nas seguintes categorias de processos [1]:

- Processos Hidrometalúrgicos: a utilização de soluções ácidas, alcalinas e mesmo neutras podem ser utilizadas como agentes lixiviantes do pó, uma vez que o zinco possui caráter anfótero [3]. Rotas hidrometalúrgicas normalmente possuem menor aplicação comercial, o que não difere nesse caso. É importante ressaltar que essas rotas geram problemas quanto ao manuseio de resíduos pós-lixiviação (a solução);

- Processos Pirometalúrgicos: trata-se de processos de maior interesse comercial devido sua maior aplicabilidade, embora, em sua maior parte, requeiram investimentos mais volumosos. Nessa categoria, enquadra-se o processo Waelz, o mais consagrado e com patentes prescritas, onde o mesmo responde atualmente pela maior parte dos métodos de reciclagem (Figura 2);

\footnotetext{
* Contribuição técnica ao 450 Seminário de Aciaria - Internacional, 25 a 28 de maio de 2014, Porto Alegre, RS, Brasil.
} 
- Estabilização química: Consiste na estabilização dos metais pesados presentes no PAE ( $\mathrm{Pb}$ e $\mathrm{Cd}$, principalmente), buscando a produção de um material que esteja adequado às exigências em relação ao seu descarte. Enquadram-se nesse processo, propostas como co-processamento do pó de aciaria em cimentos alternativos [1].

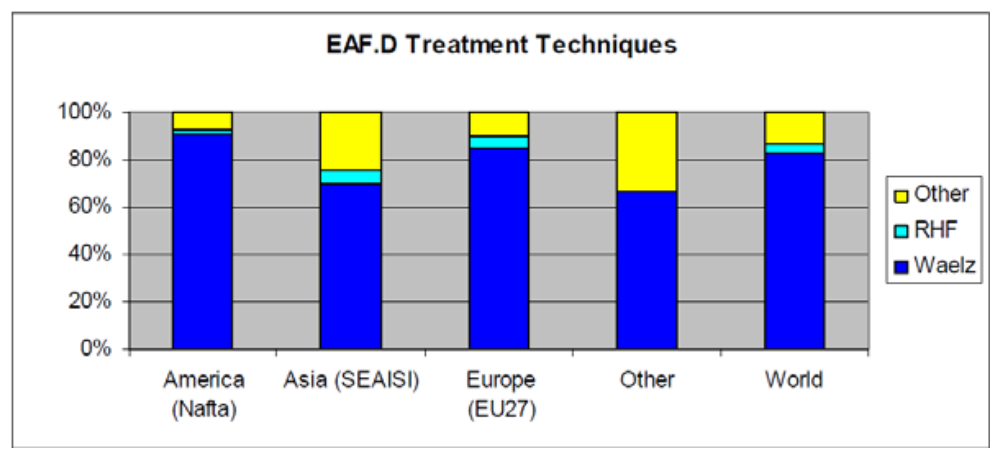

Figura 2. Técnicas de tratamento do PAE [4].

\section{MATERIAIS E MÉTODOS}

\subsection{Materiais}

No presente estudo, o material utilizado foi uma amostra de pó de aciaria elétrica cedida por uma usina siderúrgica cearense, recolhida de acordo com os requisitos exigidos segundo a norma NBR-10.007 da ABNT [6]. A referida norma estabelece que uma amostra representativa é uma parcela do resíduo a ser estudada, obtida através de um processo de amostragem, e que, quando analisada, apresenta as mesmas características e propriedades da massa total do resíduo [6]. Segue a figura que apresenta os aspectos visuais do material.

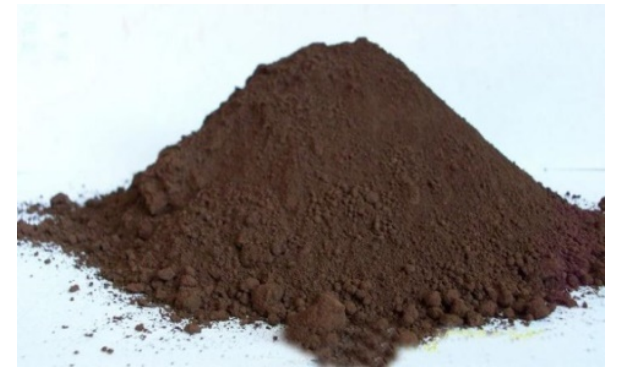

Figura 3. Foto do PAE.

\subsection{Métodos}

\subsubsection{Processamento do PAE}

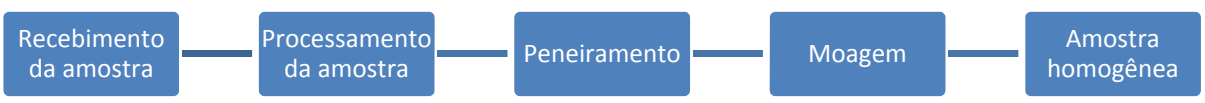

Figura 4. Fluxograma do processamento da amostra.

* Contribuição técnica ao $45^{\circ}$ Seminário de Aciaria - Internacional, 25 a 28 de maio de 2014, Porto Alegre, RS, Brasil. 
O pó de aciaria elétrica (PAE), da forma como recebida pela empresa produtora, foi submetida a procedimentos (Figura 4) que visam garantir que a amostra representativa seja homogênea.

Inicialmente, o PAE passou por uma etapa de peneiramento objetivando separar granulometricamente eventuais impurezas que possam ter sido adicionadas durante o manuseio, transporte e tempo de permanência no depósito de estocagem da empresa. Utilizou-se, para tal, uma peneira de granulometria de 170 mesh $(88 \mu \mathrm{m})$ de aço inoxidável e um agitador de peneira. O PAE, então granulometricamente definido, é encaminhado para moagem, em moinho de bolas e com tempo de operação de seis horas. Considerando que a amostra de PAE em questão é pontual em relação à empresa produtora, podendo apresentar variações quanto à composição química e as fases presentes, a homogeneização é fundamental para garantia de resultados reais.

2.2.2 Procedimentos experimentais - caracterização do PAE: difração de raios-X e fluorescência de raios- $X$

As medidas de difração de raios- $X$ foram realizadas no Laboratório de Raios-X do Departamento de Física da UFC. O equipamento utilizado foi o difratômetro para amostras policristalinas modelo DMAXB - Rigaku gerador de Raios-X de $2 \mathrm{~kW}$, com radiação de tubo de Cobalto $(\mathrm{Cu})$, CuKa1 e CuKa2, operando a 40kV e 30mA. Os padrões de difração foram obtidos no intervalo $2 \theta=5^{\circ}-120^{\circ}$ e passo de $0,02^{\circ}(2 \theta)$. A identificação das fases cristalinas presentes ocorreu mediante o uso do catálogo International Centre for Diffraction Data (ICDD) e do programa X'Pert High Score Plus.

As medidas de fluorescência de Raios-X foram realizadas no equipamento Rigaku, modelo ZSX Mini II, também pertencentes ao Laboratório de Raios-X do Departamento de Física da UFC.

\subsubsection{Levantamento de dados e de processos: estudo de processos de} aproveitamento/reciclagem do PAE

Utilização de teses de pesquisadores, de artigos de revistas internacionais, de dados termodinâmicos obtidos da literatura e de conhecimentos obtidos junto ao estudo do processamento de aço com o intuito de considerar diversas possibilidades de aproveitamento do PAE e poder sugerir rotas que sejam de interesse para a indústria. Realizou-se um banco de dados de processos de aproveitamento/reciclagem de diferentes categorias e buscou-se adaptar a caracterização do PAE em questão, realizando uma discussão sobre possibilidades, pontos favoráveis e desfavoráveis e viabilidade.

\section{RESULTADOS}

\subsection{Fluorescência de Raios-X do PAE}

A Tabela 2 apresenta os resultados de fluorescência para as seguintes amostras de PAE: (1) a amostra enviada pela empresa sem qualquer tipo de tratamento, (2) a amostra após peneiramento e homogeneização e (3) amostra retida na peneira.

\footnotetext{
* Contribuição técnica ao 45 Seminário de Aciaria - Internacional, 25 a 28 de maio de 2014, Porto Alegre, RS, Brasil.
} 
Tabela 2. Resultado da fluorescência da Poeira de aciaria elétrica para os três tipos de amostras

\begin{tabular}{|c|c|c|c|}
\hline Elementos & $\begin{array}{l}\text { PAE - empresa } \\
(\%)\end{array}$ & $\begin{array}{l}\text { PAE peneirado e } \\
\text { homogeneizado }(\%)\end{array}$ & $\begin{array}{l}\text { PAE retido na } \\
\text { peneira }(\%)\end{array}$ \\
\hline $\mathrm{Zn}$ & 45.515 & 44.358 & 38.996 \\
\hline $\mathrm{Fe}$ & 33.308 & 34.557 & 37.046 \\
\hline $\mathrm{Cl}$ & 6.2333 & 6.135 & 5.987 \\
\hline $\mathrm{Pb}$ & 3.7340 & 3.704 & 2.806 \\
\hline $\mathrm{Ca}$ & 3.4708 & 3.442 & 3.966 \\
\hline K & 2.5898 & 2.574 & 2.114 \\
\hline $\mathrm{Mn}$ & 1.4102 & 1.454 & 1.217 \\
\hline $\mathrm{Si}$ & 1.3921 & 1.418 & 1.769 \\
\hline $\mathrm{Al}$ & 0.5775 & 0.631 & 0.450 \\
\hline $\mathrm{Br}$ & 0.5254 & 0.604 & 0.479 \\
\hline$S$ & 0.5254 & 0.472 & 0.426 \\
\hline $\mathrm{Cu}$ & 0.4307 & 0.298 & 0.284 \\
\hline $\mathrm{Ti}$ & 0.1480 & 0.178 & 0.211 \\
\hline $\mathrm{Cr}$ & 0.2064 & 0.169 & 0.229 \\
\hline$P$ & 0.1579 & - & 0.132 \\
\hline $\mathrm{Na}$ & - & - & 3.883 \\
\hline
\end{tabular}

Os resultados de fluorescência apresentam a composição química elementar do resíduo, confirmando o zinco e o ferro como os principais elementos componentes da amostra de PAE.

O resíduo analisado apresenta uma composição consistente com os resíduos gerados na produção de aços carbono, com especial destaque aos teores de $\mathrm{Zn}$ superiores aos mais comumente encontrados. Destaca-se, também, a presença do $\mathrm{Pb}$, confirmando a periculosidade do resíduo, ainda que o percentual em massa desse elemento estejam dentro da faixa média para a PAE.

Um dado relevante sobre as amostras está no teor de $\mathrm{Zn}$ presente. A elevada concentração desse elemento, aproximadamente $30 \%$ superior ao conteúdo de ferro, evidencia o aumento no uso de sucata galvanizada pela empresa geradora do resíduo. Além disso, a porcentagem de ferro, ainda que dentro dos valores encontrados para esse tipo de resíduo, sugere uma perda potencial do elemento que é constituinte principal do produto final da empresa, aço.

A amostra após peneiramento e homogeneização demonstra que o tratamento da amostra agiu de forma positiva, diminuindo a concentração de parte dos elementos considerados traço (chegando ao ponto do elemento $P$ não ser detectado na amostra peneirada). O aumento na concentração de ferro e de outros elementos está associado à diminuição da massa dos outros componentes do resíduo, uma vez que a fluorescência trabalha com a concentração em massa dos elementos analisados.

No caso da amostra retida na peneira, destaca-se a presença do elemento $\mathrm{Na}$, normalmente presente no PAE, porém que não havia sido detectado nas duas

* Contribuição técnica ao 450 Seminário de Aciaria - Internacional, 25 a 28 de maio de 2014, Porto Alegre, RS, Brasil. 
amostras anteriores. Possivelmente esse elemento encontrava-se muito disperso na amostra oriunda da empresa, estando abaixo do limite de detecção do equipamento de fluorescência. $O$ ato de peneirar pode ter concentrado esse elemento na amostra de material retida na peneira, uma vez que o volume da amostra retida é consideravelmente inferior.

\subsection{Difração de Raios-X da Amostra de PAE Peneirada e Homogeneizada}

O difratograma a seguir apresenta o resultado da medida de difração de Raios-X para a amostra de PAE peneirada e homogeneizada, mostrado na Figura 5.

A identificação de fases indicou que o zinco presente na amostra encontra-se distribuído, provavelmente nas fases de Zincita $(\mathrm{ZnO})$ e ferrita de zinco $\left(\mathrm{ZnFe}_{2} \mathrm{O}_{4}\right)$. $\mathrm{O}$ ferro contido está distribuído nas fases de ferrita de zinco $\left(\mathrm{ZnFe}_{2} \mathrm{O}_{4}\right)$, magnetita $\left(\mathrm{Fe}_{3} \mathrm{O}_{4}\right)$, wustita $(\mathrm{FeO})$ e hematita $\left(\mathrm{Fe}_{2} \mathrm{O}_{3}\right)$ em caráter não estequiométrico. A Figura 6 mostra o difratograma após a análise com o programa X'Pert High Score Plus, utilizado para a identificação de fases no PAE estudado. Além disso, observa-se a presença de outras fases cristalinas, como $\mathrm{PbO}, \mathrm{KCl}$, e $\mathrm{Mn}_{2} \mathrm{O}_{3}$.

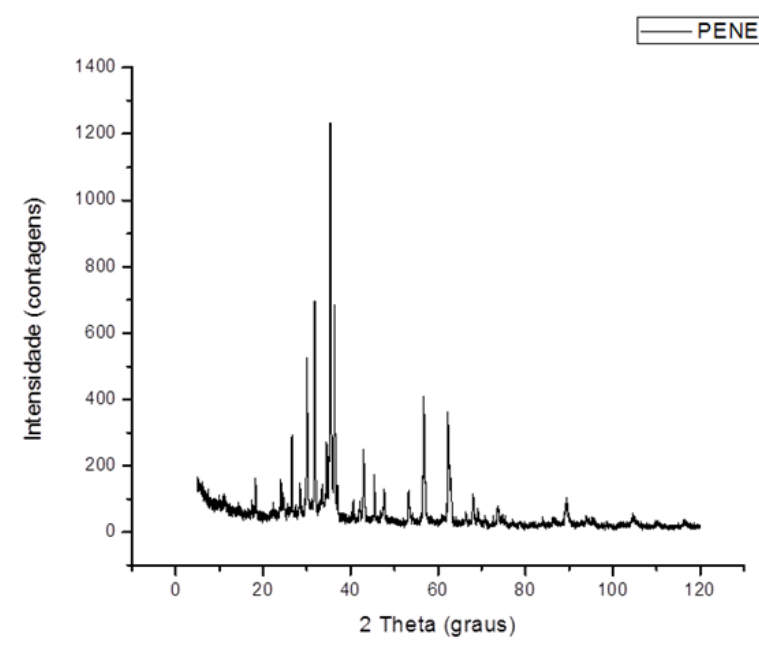

Figura 5. Difratograma da amostra de PAE estudada, peneirada e homogeneizada.

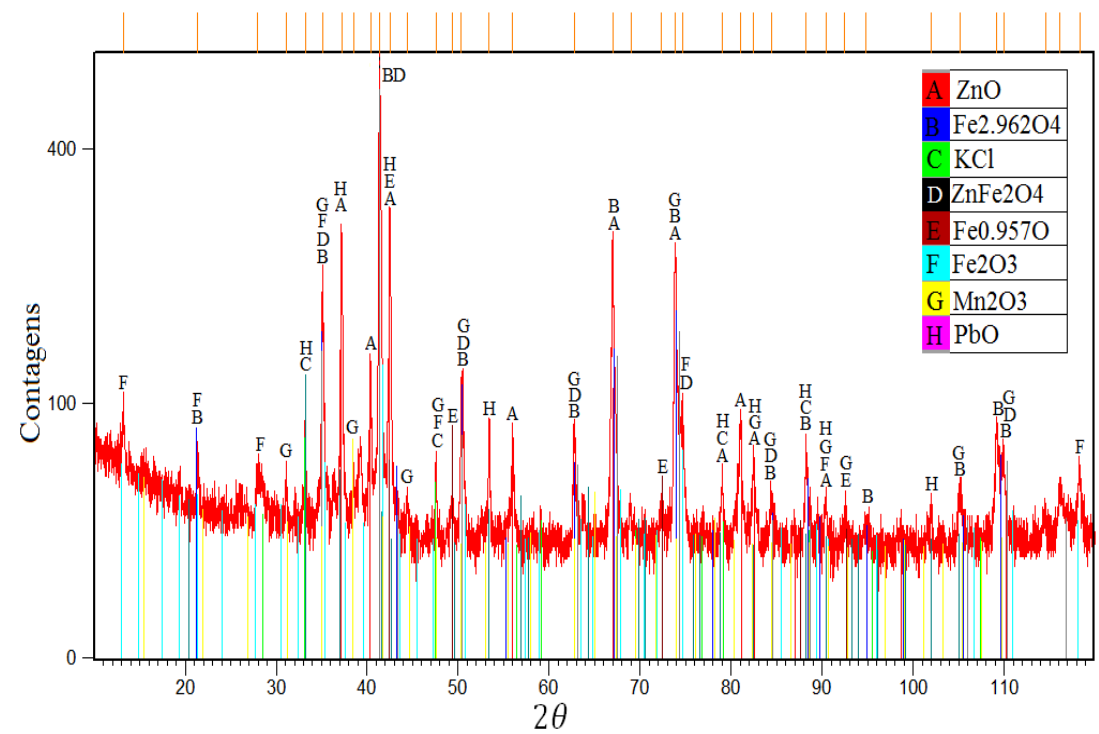

Figura 6. Difratograma do PAE analizado. Identificação das fases cristalinas constituintes do PAE.

\footnotetext{
* Contribuição técnica ao $45^{\circ}$ Seminário de Aciaria - Internacional, 25 a 28 de maio de 2014 Porto Alegre, RS, Brasil.
} 


\section{DISCUSSÃO}

\subsection{Estudo da Viabilidade de Processos de Aproveitamento/Reciclagem do PAE Baseado nos Resultados Obtidos da Caracterização}

O estudo buscou em uma série de bancos de dados e processos contendo importantes publicações - revistas internacionais, dissertações de mestrados, teses de doutorado - e, aqui, concentram nossas discussões levando a amostra caracterizada em consideração.

Uma vez que a condução do processo de maneira ineficaz pode resultar em problemas maiores, o desenvolvimento de um material utilizando resíduo como matéria-prima passa pelo estudo de vários aspectos, tais como:

i) O processo de geração do resíduo;

ii) Composição do resíduo;

iii) Caracterização do resíduo: composição completa (incluindo traços de espécies ambientalmente relevantes), análise microestrutural (incluindo determinação de fases mineralógicas), características físicas (densidade, granulometria e viscosidade);

iv) Seleção das possíveis aplicações;

v) Desenvolvimento do produto;

vi) Avaliação do desempenho do produto (inclui-se a aceitação e a compatibilidade do mercado);

vii) Avaliação de compatibilidade ambiental no processo global.

Nosso estudo encontra-se na fase (iv) e em processo de desenvolvimento, ressaltando a impossibilidade de generalização de processos para esse resíduo, uma vez que a composição variável e a presença de espécies ambientalmente importantes (como $\mathrm{Pb}$, por exemplo) podem dificultar o enquadramento do mesmo em alguma rota utilizada em situações distintas.

\subsubsection{Reciclagem de PAE como matéria-prima na fabricação de materiais cerâmicos argilosos (cerâmica vermelha)}

O processo em questão foi adotado laboratorialmente por uma equipe da UFRGS que se utilizava de uma amostra de uma produtora local de aços e estudado durante uma tese de doutorado [1]. Nesse trabalho, voltou-se a atenção para o zinco e a sua imobilização nas massas cerâmicas - a amostra em questão possuía concentração de zinco da ordem de $13 \%$, bem inferior ao do presente trabalho ( $\approx 45 \%)$. Sendo um metal volátil, com ponto de fusão da ordem de $420^{\circ} \mathrm{C}$, a concentração deste resíduo pode gerar emissões atmosféricas durante a queima de formulações cerâmicas.

A obtenção de produtos de cerâmica vermelha ocorre por meio de etapas sequenciais que são apresentadas no fluxo esquemático a seguir.

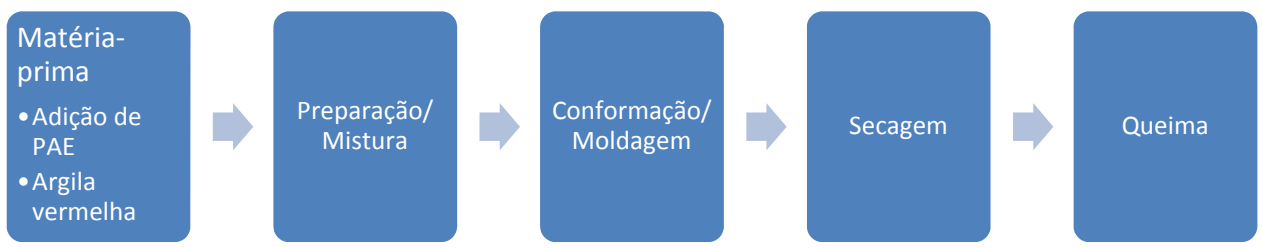

Figura 7. Fluxograma da produção de materiais cerâmicos.

\footnotetext{
* Contribuição técnica ao 450 Seminário de Aciaria - Internacional, 25 a 28 de maio de 2014 Porto Alegre, RS, Brasil.
} 
A produção de corpo-de-prova testes consiste nas formulações em peso variando de $0 \%$ (amostra base) a 30\% de PAE (mistura realizada em moinho de bolas), conformação em prensas hidráulicas, secagem livre ao ar (24h), seguida por uma secagem em estufa $\left(110^{\circ} \mathrm{C}, 24 \mathrm{~h}\right)$ e a queima - sinterização a $850^{\circ} \mathrm{C}, 950^{\circ} \mathrm{C}$ e $1050^{\circ} \mathrm{C}$ em um patamar de queima de $2 \mathrm{~h}$. Após, realiza-se ensaios de acordo com normas técnicas e procedimentos laboratoriais para determinação das propriedades tecnológicas e observação da imobilização do zinco (emissão de voláteis).

A análise da resistência mecânica e da absorção de água, como principais propriedades tecnológicas, demonstrou efeito positivo das adições de PAE, com valores obtidos de acordo com a norma regulamentadora da ABNT [7]. A análise da imobilização do zinco, por meio de testes de lixiviação (NBR 10005 [8]) e de solubilização (NBR 10006 [9]), mostrou resultados dentro dos limites estabelecidos pela norma NBR 10004 [2]. Concluiu-se que o PAE adicionado a argila vermelha, de acordo com as normas brasileiras, pôde ser enquadrado como resíduo classe II A (inerte). Quanto às emissões atmosféricas, a análise durante a queima em forno mufla, mostrou que os valores do ensaio encontram-se abaixo do estabelecido pelas resoluções do CONAMA, especialmente a Resolução n.316 [10].

A simplicidade e praticidade do método sugerem a idéia de um processo ideal, mas os principais problemas quanto à adequação direta desse meio estudado ao nosso PAE em questão encontram-se:

i) Nas composições distintas, fazendo com que seja necessário uma avaliação específica do PAE e da argila, além de se fazer necessário um estudo para emissões de outros metais, em especial o $\mathrm{Pb}$ - metal pesado com fator ambiental fundamental;

ii) No fato de as empresas produtoras necessitarem adequar-se para o armazenamento dessa matéria-prima que é um resíduo industrial perigoso, necessitando de investimentos, muitos dos quais não estão nos patamares desses produtores. Além disso, é necessário acompanhamento tecnológico das emissões atmosféricas e da imobilização dos metais que garanta que índices de acordo com a legislação ambiental nacional e regional sejam obtidos.

\subsubsection{Incorporação de PAE em blocos de pavimentação}

A incorporação de PAE em blocos de pavimentação, a exemplo do processo anterior, foi estudada nos laboratórios da UFRGS e tema de dissertação de mestrado [11]. O processo, conduzido de maneira semelhante ao anterior, apresentou resultados positivos nas propriedades dos blocos. O grande problema desse método consistiu na incoerência com o padrão estabelecido pela norma NBR 10006 [9] - ensaio de solubilização - e os valores estabelecidos pela norma NBR 10004 [2], adequando o material como classe II B (não inerte), o que pode significar a não imobilização completa dos resíduos e de seus elementos mais danosos ambientalmente.

Ambas as atividades de incorporação descritas apresentam problemáticas quanto à dificuldade de generalização, devido à variabilidade comprovada de PAEs. Outro problema é acordar com uma empresa, que possua a licença ambiental requerida pelos órgãos regulamentadores, capaz de responsabilizar-se pela totalidade do resíduo.

\subsubsection{Fabricação de clínquer}

Segue a mesma linha dos processos já citados e representa um co-processamento comum a escórias na indústria siderúrgica: a fabricação de clínquer. Sendo

\footnotetext{
* Contribuição técnica ao 45 Seminário de Aciaria - Internacional, 25 a 28 de maio de 2014, Porto Alegre, RS, Brasil.
} 


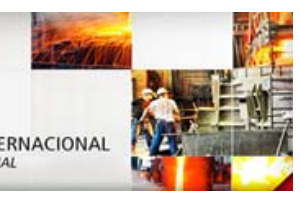

estudado em uma tese de doutorado que se propôs a determinar o efeito positivo do $\mathrm{ZnO}$ - zincita, principal fase encontrada no PAE - nas propriedades finais do clínquer [11]. Destaca-se que o PAE acaba atuando como um retardador de pega do cimento, sendo proposto um modelo próprio de hidratação das pastas de cimento. Há um problema sobre a presença de cloretos no PAE, que acaba por aumentar o gasto energético e prejudica o processo de hidratação se comparados a cimentos sem adições. Isso inclui a necessidade de um pré-processamento do PAE, com especial atenção a cloretos e metais pesados $(\mathrm{Pb})$.

\subsubsection{Fabricação de ligas ZAMAC}

Neste processo, o PAE seria matéria-prima para a produção de ligas ZAMAC, que são ligas de zinco contendo também em menores quantidades alumínio, magnésio e cobre. As ligas ZAMAC possuem diversas aplicações, sendo utilizadas em processos de fundição sob pressão (injeção) para a produção de fivelas de cintos, acessórios para calçados, acessórios para móveis, etc. A presença de $\mathrm{Pb}$ em produtos de uso doméstico seria um grande problema. Métodos deveriam ser estudados para a separação eficaz do zinco dos outros diversos componentes do $\mathrm{PAE}$, com especial atenção para o $\mathrm{Pb}$ e o $\mathrm{Fe}$ (que não faz parte da composição das ligas ZAMAC).

\subsubsection{Retorno ao processo produtivo}

O retorno ao processo produtivo na forma de briquetes compósitos com carepa e redutores é uma técnica bastante comum para PAEs com baixos teores de $\mathrm{Zn}$. Ela permite a recirculação do PAE e o acúmulo e enriquecimento do mesmo em zinco, possibilitando sua utilização em processos de extração/obtenção do mesmo. Logo, nota-se que o acúmulo/enriquecimento também ocorrerá para outros elementos, em especial o $\mathrm{Cl}$ e o $\mathrm{Pb}$. Esse último fato inviabiliza o processo para a amostra, tendo em consideração que nossos teores desses elementos são elevados, além de que o teor de Zn (principal objetivo desse processo) já é elevado e adequado a processos de aproveitamento/reciclagem.

\subsubsection{Processo Waelz}

Consagrado e com patentes prescritas, é a mais aplicada tecnologia dos processos pirometalúrgicos de recuperação de poeiras siderúrgicas, em especial do PAE [12]. Possui diversas versões comerciais que objetivam a reciclagem na cadeia produtiva do zinco. O processo pirometalúrgico em questão consiste na volatilização de metais não ferrosos ( $\mathrm{Zn}, \mathrm{Pb}, \mathrm{Cd}$ etc.) a partir de uma mistura sólida de óxidos reduzidos por um agente redutor (coque, carvão vegetal) em um forno rotativo, obtendo óxido de zinco, precipitados de chumbo $\left(\mathrm{PbSO}_{4}\right)$, sais mistos de cloretos e uma escória Waelz (contendo ferro e que pode ser aplicada em cimento e em pavimentação). A planta Waelz consiste normalmente em duas, algumas vezes três, partes: (i) a preparação da matéria-prima - garantir homogeneização e estabilidade do material de alimentação; (ii) a unidade Waelz - que transforma a matéria-prima em uma escória Waelz e um óxido Waelz por meio de um forno rotativo, que é carreado com gás; (iii) e uma eventual lavagem da poeira de ZnO bruto para de-halogenização que visa a adequação do óxido Waelz diretamente a fundições de zinco ou usos químicos.

Sendo naturalmente um elo estratégico entre as indústrias do aço e do zinco, o processo, que visa recuperação de $\mathrm{ZnO}$, é uma rota interessante, já que o PAE em

* Contribuição técnica ao 450 Seminário de Aciaria - Internacional, 25 a 28 de maio de 2014, Porto Alegre, RS, Brasil. 
estudo possui cerca de $45 \%$ de $\mathrm{Zn}(\approx 53 \% \mathrm{ZnO}$, se considerado que cerca de $95 \%$ do Zn está na forma de zincita).

As problemáticas estão por conta do alto teor de cloretos, conforme análise, que demanda maior número de etapas para adequação do resíduo (etapa para dehalogenização posterior), além de possível maior consumo energético; e por conta do alto investimento necessário para montar-se uma planta para o processo. A alternativa de utilizar a planta já existente no Brasil, localizada em Juiz de Fora (MG), é inviável pela logística de transporte necessária devido a grande distância entre a fornecedora de PAE (CE) e a planta (MG).

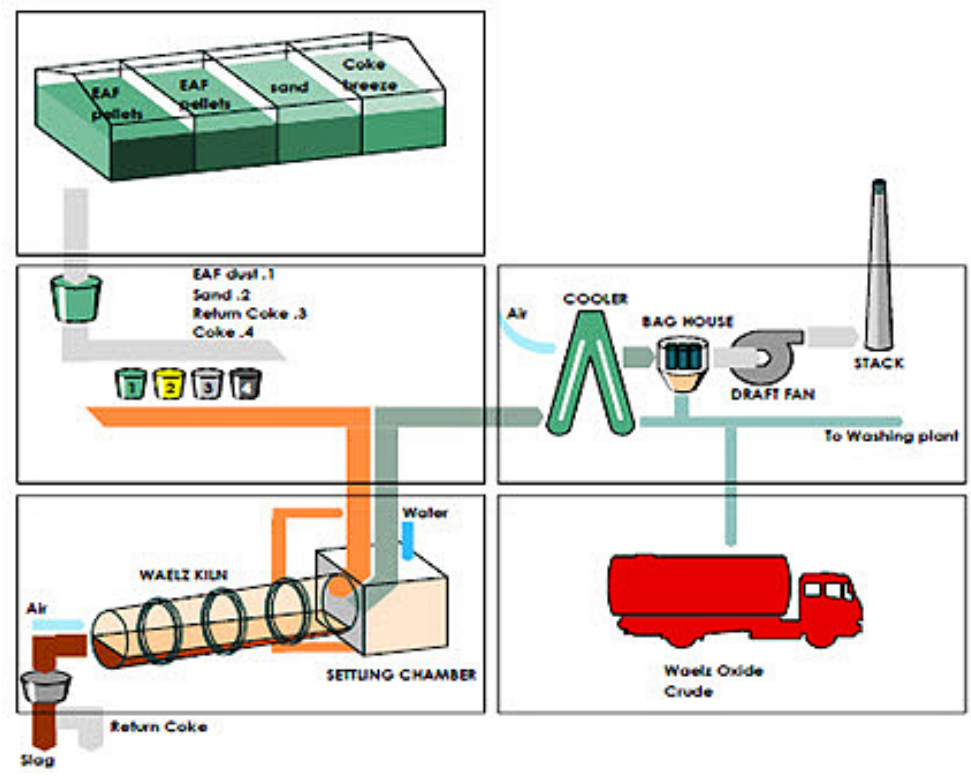

Figura 8. Planta Waelz [12].

\subsubsection{Processos hidrometalúrgicos}

Há uma série extensa de soluções e pHs utilizados em processos hidrometalúrgicos com o objetivo de tratar a poeira de aciaria elétrica e fazer uma lixiviação específica. O motivo do extenso uso e estudo desses processos encontram-se na sua simplicidade de implementação em pequenas escalas e no seu baixo custo se comparado a processos pirometalúrgicos.

Em nosso estudo, destaca-se um processo utilizado em uma planta australiana, publicado em uma revista internacional de especial destaque [13]. Na publicação em questão, o processo é esquematizado conforme o fluxograma a seguir.

Esse processo possui estudos que demonstram redução de até $99,9 \%$ do teor de cloretos no resíduo e tem por objetivo obter: i) um composto com altos teores de $\mathrm{Zn}$ e baixos de $\mathrm{Fe}$ e $\mathrm{Cl}$ (não magnético), adequado para tratamento em fundições $\mathrm{Zn}-\mathrm{Pb}$; ii) um composto de altos teores de $\mathrm{Fe}$ e baixos de $\mathrm{Zn}$ adequados para aterros; e iii) águas residuais tratadas para descarte em esgotos [13].

As grandes problemáticas desse processo são comuns em todos os processos hidrometalúrgicos: a baixa granulometria do PAE e a necessidade de grandes quantidades de soluções reagentes são consideravelmente pontos negativos. Especificamente para o PAE em questão, a grande quantidade de cloretos impurifica rapidamente as soluções de tratamento, aumentando os gastos com a planta. $\mathrm{O}$ processo também gera um resíduo líquido que deve ser adequado ao descarte.

* Contribuição técnica ao 450 Seminário de Aciaria - Internacional, 25 a 28 de maio de 2014, Porto Alegre, RS, Brasil. 


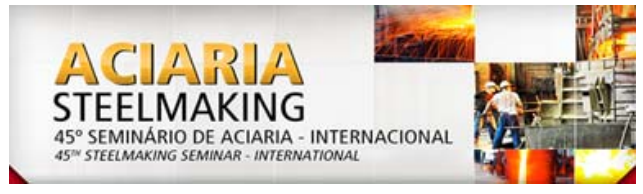

\section{CONCLUSÃO}

No presente trabalho, ainda em desenvolvimento, uma amostra de pó de aciaria elétrica coletada de uma mini-mill cearense foi caracterizada por difração e fluorescência de raios- $x$. O alto porcentual de zinco é surpreendente, e reflete a utilização de sucata galvanizada. O resíduo possui grande potencial como fonte de zinco. No entanto, há a necessidade de métodos de tratamento para lidar com o alto teor de chumbo e o de cloretos.

Mais estudos são necessários para definir uma possibilidade de aproveitamento/reciclagem do pó de aciaria elétrica em questão.

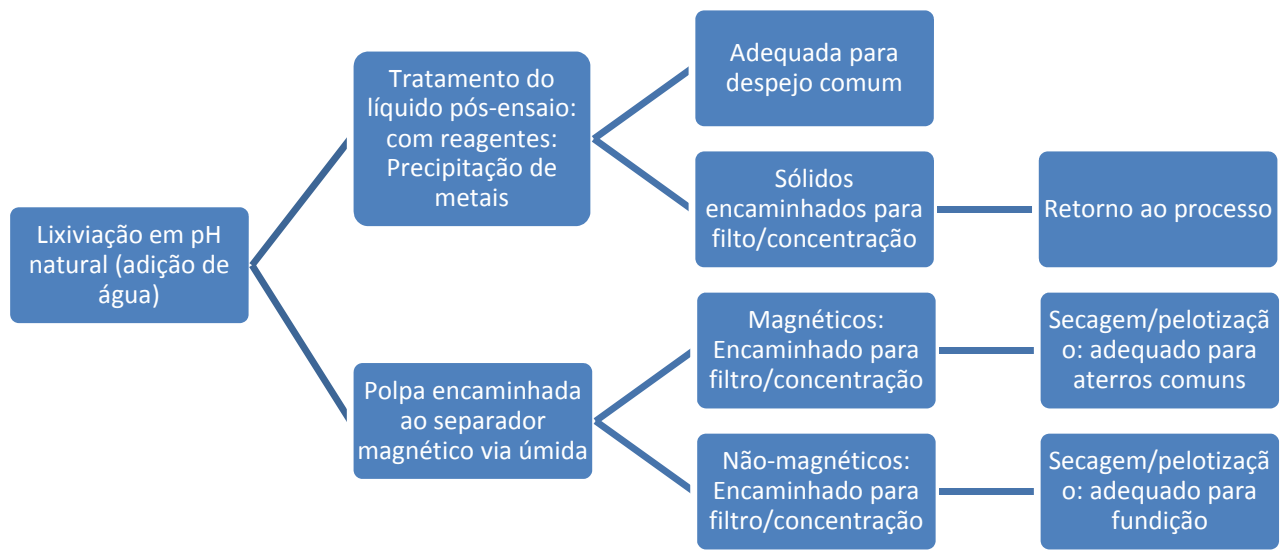

Figura 9. Fluxograma de processo hidrometalúrgico via $\mathrm{pH}$ natural [13].

\section{REFERÊNCIAS}

1 Silva MC. Reciclagem do pó de aciaria elétrica como matéria-prima na fabricação de materiais cerâmicos argilosos: controle das emissões atmosféricas de zinco [tese de doutorado em Engenharia]. Porto Alegre: PPGE3M, UFRGS; 2006.

2 Associação Brasileira de Normas Técnicas. ABNT NBR 10004: Resíduos Sólidos Classificação. Rio de Janeiro; 2004.

3 Nyirenda RL. The processing of steelmaking flue-dust: A review. Mineral Engeneering 4. 1991;7-11:1003-25.

4 Rütten J. Application of the Waelz technology on resource recycling of steel mill dust. Düsseldorf: ValoRes $\mathrm{GmbH} ; 2006$.

5 Moraes CAM, Brehm F, Graffitti D, Vilela ACF. Estado da arte da reciclagem e reutilização de resíduos sólidos de aciaria elétrica - Uma ou várias linhas de ação?. In: ABM. $57^{\circ}$ Congresso Anual ABM - Internacional; 2002; São Paulo, Brasil. São Paulo: ABM; 2002.

6 Associação Brasileira de Normas Técnicas. ABNT NBR 10007: Amostragem de resíduos sólidos. Rio de Janeiro; 2004.

7 Associação Brasileira de Normas Técnicas. ABNT 18810: Valores limites característicos de produtos cerâmicos estruturais. Rio de Janeiro; 2006.

8 Associação Brasileira de Normas Técnicas. ABNT NBR 10005: Procedimento para obtenção de extrato lixiviado de resíduos sólido. Rio de Janeiro; 2004.

9 Associação Brasileira de Normas Técnicas. ABNT NBR 10006: Procedimento para obtenção de extrato solubilizado de resíduos sólidos. Rio de Janeiro; 2004.

10 CONAMA. Resolução CONAMA n. 316: Dispõe sobre procedimentos e critérios para o funcionamento de sistemas de tratamento térmico de resíduos. 29 de outubro de 2002.

\footnotetext{
* Contribuição técnica ao 450 Seminário de Aciaria - Internacional, 25 a 28 de maio de 2014, Porto Alegre, RS, Brasil.
} 
11 Vargas AS. Estudo da viabilidade do uso do pó de aciaria elétrica a arco na confecção de blocos de concreto para pavimentação [dissertação de mestrado em Engenharia]. Porto Alegre: PPGE3M, UFRGS; 2002.

12 RütteNJ. Application of pyrometallurgycal processes on resourve recycling of steel mill dust. Dusseldorf: ValoRes $\mathrm{GmbH} ; 2006$.

13 Bruckard WJ, Davey KJ, Rodopoulos T, Woodcocka JT, Italiano J. Water leaching and magnetic separation for decreasing the chloride level and upgrading the zinc content of EAF steelmaking baghouse dusts. International Journal of Mineral Processing. 2005;75:1-20.

* Contribuição técnica ao 45 Seminário de Aciaria - Internacional, 25 a 28 de maio de 2014, Porto Alegre, RS, Brasil. 